\title{
Wives and Midwives
}


Comparative Studies of Health Systems and Medical Care

\author{
General Editor \\ Charles Leslie
}

Editorial Board

Fred DunN, M.D., University of California, San Francisco

RenÉE Fox, University of Pennsylvania

Eliot Freidson, New York University

EDWARD MONTGOMERY, Washington University

Yasuo OTSUKA, M.D., Yokohama City University Medical School

Carl E. Taylor, M.D., The Johns Hopkins University

K. N. UduPA, M.S., F.R.C.S., Banaras Hindu University

Paul U. Unschuld, University of Munich

John M. Janzen, The Quest for Therapy in Lower Zaire

Paul U. Unschuld, Medical Ethics in Imperial China: A Study in Historical Anthropology

Margaret M. Lock, East Asian Medicine in Urban Japan: Varieties of Medical Experience

Jeanie Schmit Kayser-Jones, Old, Alone, and Neglected: Care of the Aged in Scotland and in the United States

Arthur Kleinman, Patients and Healers in the Context of Culture: An Exploration of the Borderland Between Anthropology, Medicine and Psychiatry

Stephen J. Kunitz, Disease Change and the Role of Medicine: The Navajo Experience

Carol Laderman, Wives and Midwives: Childbirth and Nutrition in Rural Malaysia 


\section{Wives and Midwives}

Childbirth and Nutrition in

Rural Malaysia

Carol Laderman

University of California Press

Berkeley · Los Angeles • London 
University of California Press

Berkeley and Los Angeles, California

University of California Press, Ltd.

London, England

Copyright (C) 1983 by The Regents of the University of California

Library of Congress Cataloging in Publication Data

\section{Library of Congress Cataloging in Publication Data}

Laderman, Carol.

Wives and midwives.

(Comparative studies of health systems and medical care)

Bibliography: p. 247

Includes index.

1. Malays (Asian people)-Medicine.

2. Birth customs-Malaysia-Terengganu.

3. Food habits-Malaysia-Terengganu.

4. Puerperium-Nutritional aspects.

5. Kampong Merchang (Terengganu)_-Social life and customs.

1. Title. II. Series. [DNLM: 1. Midwifery.
[D.

2. Pregnancy. 3. Nutrition surveys-Malaysia.

4. Rural health-Malaysia.

5. Anthropology, Cultural-Malaysia. GN635.M4 L154c]

$\begin{array}{llll}\text { GN635.M4L33 } & 1983 & 306^{\prime} .46 & 83-47664\end{array}$

ISBN 0-520-04924-1

Printed in the United States of America

$\begin{array}{lllllllll}1 & 2 & 3 & 4 & 5 & 6 & 7 & 8 & 9\end{array}$ 
For Gabriel, my husband and best friend. 
